\title{
ISSUES IN PUBLIC HEALTH \\ A total ban on alcohol advertising: Presenting the public health case
}

\author{
Charles Parry, Nadine Harker Burnhams, Leslie London
}

Evidence from burden of disease and economic costing studies amply indicate that the public health burden from hazardous and harmful use of alcohol in South Africa warrants drastic action. Evidence that banning alcohol advertising is likely to be an effective intervention is reflected in WHO strategy documents on non-communicable diseases and harmful use of alcohol. Studies on young people furthermore support arguments refuting the claim that advertising only influences brand choice. Given the weakness of relying on industry self-regulation, the government is considering legislation to ban alcohol advertising, resulting in heated debate. Tobacco control and studies investigating the effect of alcohol advertising bans on consumption and alcoholrelated deaths point to the effectiveness of such action - ideally supplemented by other policy interventions. Arguments against an advertising ban include possible communication sector job losses, but these are likely to have been exaggerated. Banning alcohol advertising will necessitate greater scrutiny of digital media, satellite television and merchandising to reduce the likelihood of subverting the ban.

S Afr Med J 2012;102(7):602-604.
Twenty-three years after a South African Medical Journal article called for a ban on tobacco advertising, ${ }^{1}$ ample evidence indicates that the severe public health burden from hazardous and harmful use of alcohol in South Africa warrants the same drastic action. While abstention from drinking is high, South Africa is among the countries having the highest consumption of absolute alcohol per drinker per year, the second highest category of harmful patterns of drinking, and the highest category for past year heavy episodic drinking. ${ }^{2}$ While liquor producers profit substantially from their customers engaging in heavy drinking episodes, this behaviour places an enormous burden on the country. Rehm et al. ${ }^{3}$ found that, in 2004, alcohol accounted for $6.3 \%$ of DALYs lost in South Africa (i.e. years of life lost through dying prematurely) because of an alcohol-related event or living with a disability caused by alcohol. About 130 people die daily as a result of alcohol-related causes, $46 \%$ from injuries, 35\% from tuberculosis (TB) and HIV/AIDS, and 15\% from non-communicable diseases such as cancer and liver and cardiovascular diseases. ${ }^{3}$ The resulting economic costs are enormous, with alcohol estimated to

Charles Parry is Director of the Alcohol \& Drug Abuse Research Unit (ADARU) at the Medical Research Council (MRC) and an Extraordinary Professor in the Department of Psychiatry at Stellenbosch University. His interests include substance abuse epidemiology, alcohol and drug policy, and the effect of substance abuse on HIV and AIDS. Nadine Burnhams is a senior scientist at ADARU (MRC). Her interests are in improving the quality of substance abuse prevention services and designing and implementing substance abuse prevention services for the corporate sector. Leslie London is Professor in Public Health in the School of Public Health and Family Medicine, University of Cape Town, and a public health specialist with the Western Cape Department of Health. He is involved in research into pesticide hazards and health needs of farm workers, including alcohol abuse problems. have cost provincial health departments and the national Department of Health in 2009 R6.1 billion and R0.5 billion, respectively. ${ }^{4}$ Currently, about R2 billion is spent annually on alcohol marketing in South Africa, with sports sponsorships accounting for some $30 \%{ }^{5}$

A comprehensive review of policies and programmes indicates that making alcohol less available and more expensive and placing a ban on alcohol advertising are the most cost-effective ways to reduce the harm caused by alcohol. ${ }^{6}$ This position is reflected in WHO policy documents, namely the Global Strategy to Reduce the Harmful Use of Alcohol and the Global Status Report on Noncommunicable Diseases 2010. ${ }^{8}$ The latter rates enforcing bans on alcohol advertising as among the top 10 'best buys' for addressing non-communicable diseases. Apart from Islamic countries, several others restrict alcohol advertising. France, for example, restricts the content of radio and print advertisements to specific elements such as product name, ingredients, alcohol strength, method of production and conditions of sale; and requires that advertisements include moderation messages. ${ }^{9}$ Norway and Sweden prohibit advertising to the public of alcoholic beverages over $2.5 \%$ alcohol by volume in Norway, and 3.5\% in Sweden. ${ }^{9}$

The alcohol and allied industries have been accused of promoting ineffective voluntary codes on marketing to keep governments from imposing stricter regulations..$^{10} \mathrm{~A}$ comprehensive project investigating alcohol marketing in 5 European countries was reported in April 2012. It concluded that self-regulation for alcohol advertising and promotion does not protect young people against exposure to alcohol commercials. ${ }^{11}$ In South Africa, alcohol advertisements are subject to the code of the Advertising Standards Authority of South Africa (ASA), a body set up and paid for by the marketing communication industry to ensure that its system of self-regulation works in the public interest. ${ }^{12}$ The Industry Association for Responsible Alcohol Use (ARA), which is funded by the major alcohol producers in South Africa, is a member of the ASA. Therefore, it is not surprising that alcohol advertisements are permitted that link their products to things that have nothing to do with the intrinsic properties of the products or their manufacture, but rather to notions such as financial and social success (even happiness), sex, patriotism, and mocking people who buy beer in 340 $\mathrm{ml}$ containers rather than $750 \mathrm{ml}$ bottles, or who choose to drink milk rather than beer while watching sporting events. Particularly worrying, there appears to be scant regard to the large underage proportion of 
the audience of alcohol marketing campaigns, ${ }^{13}$ beyond sometimes including in small print at the bottom of the advertisement 'Not for sale to persons under the age of 18 '.

Contrary to the liquor industry's view that alcohol advertising only influences brand choice, studies in several countries established that alcohol advertising influences young people's behaviour; ${ }^{14-16}$ it normalises drinking in many different settings, brings about positive beliefs about drinking, and encourages young people to drink alcohol sooner and in greater quantities. ${ }^{14}$ Internal alcohol industry documents accessed in the UK included many references to the need to recruit new drinkers (rather than just motivating existing drinkers to switch brands) and campaigns aimed to appeal to youth, with market research data on 15 - 16-year-olds being used to guide the development of such campaigns. ${ }^{17}$ The fivecountry study concluded that young people between 13 and 17 years were expressly targeted by alcohol advertisers. ${ }^{11}$

The liquor industry differs from the public health community in how it sees alcohol problems and how they should be addressed. ${ }^{18}$ The industry frames the problem as drinking being 'normal' and that problems only arise because of a minority of individuals misusing its products. It sees the solution largely as involving changing the behaviour of this minority through education. In contrast, the public health approach looks more broadly at the host (the drinker), the product (alcohol) and the environment. The latter includes alcohol advertising. The public health approach aims to make the environment less 'pro-alcohol' and reduce hazardous and harmful drinking through measures to shift the population curve for per capita consumption of alcohol downwards.

The government's Inter-Ministerial Committee on Substance Abuse, and the Minister of Health in particular, follow this broader approach and, for more than a year, have indicated their intention to tighten alcohol advertising restrictions. This has been spurred by international calls for countries to upscale efforts to address the harmful use of alcohol, ${ }^{7,19}$ the successes achieved following implementation of control measures on tobacco, including banning advertising ${ }^{20}$ and, especially, the resolutions from the 2nd Biennial Anti-Substance Abuse Summit in Durban in 2011. ${ }^{21}$ Recommendations included: banning all advertising of alcoholic products in public and private media, including electronic media; banning all sponsorship by the alcohol industry of sports, recreation, arts and cultural and related events; restrictions on the accessibility of alcohol; harmonisation of laws and policies regarding the sale of alcohol; reducing the number of liquor outlets; raising the legal age for purchasing and public consumption of alcohol; raising taxes on alcohol products; and reducing the current legal alcohol limit for drivers.

In April 2012, the draft Control of Marketing of Alcoholic Beverages Bill was leaked to the press. ${ }^{5}$ This draft bill signals the government's intention to seriously consider banning alcohol advertising by seeking to 'totally prohibit the advertising of alcoholic products; permit only notices, which must be limited to "describing the price, brand name, type, strength of origin and composition of the product", to be displayed inside licensed and registered premises, and notices must be accompanied by a health warning and must not be visible from the outside; prohibit the display of names and logos of alcoholic beverages on delivery vehicles; prohibit the linking of sports sponsorships to alcoholic brand names; and prohibit the promotion of alcoholic beverages through donations and discounts at events. ${ }^{5}$ This provoked a massive outcry from the liquor industry, sporting bodies and the advertising sector. The draft bill may, however, be modified before it goes to Cabinet, and a process involving stakeholder consultation is also probable before it is finalised. ${ }^{5}$

Tighter restrictions on alcohol advertising are a certainty, but a key question is whether a total ban will achieve the public health benefits that the Minister of Health and others propose; or can they be achieved through other means? Alternative strategies could include increasing funding for counter-advertisements and a partial ban or other restrictions on alcohol advertising, such as independent pre-vetting of alcohol advertisements by a body with less vested interest than the liquor industry itself, ARA or ASA; banning liquor advertisements flighted on radio and television before 9 or $10 \mathrm{pm}$; and banning alcohol advertising where more than $15 \%$ of the audience is likely to be under-age.

Local evidence is that the package of controls on tobacco products implemented during the late 1990s and 2000s, including price increases and a total ban on tobacco advertising, led to decreased smoking rates in some groups. ${ }^{22}$ Evidence gathered from a review of time series data from 20 countries collected over 26 years demonstrates that a total ban results in reduced consumption. ${ }^{23}$ A meta-analysis of 322 estimated advertising elasticities found a positive effect of advertising on consumption. ${ }^{24}$ Decreased alcohol consumption leads to decreased health problems. ${ }^{25}$ Hollingworth $e t$ al. ${ }^{26}$ through a comprehensive modelling study in the USA, found that a complete ban on alcohol advertising would reduce deaths from harmful drinking by $16 \%$ over the lifetime of the cohort studied, and mortality would be further reduced by adding tax increases. In contrast, a partial ban would only result in a $4 \%$ reduction in alcoholrelated lives lost. Partial bans (e.g. limiting the time for flighting advertisements till after a certain time in the evening) have also been criticised for having limited efficacy, given the innovative ways that alcohol producers have worked around such bans. ${ }^{11}$

The evidence therefore supports a broad public health approach to addressing harmful use of alcohol rather than simply seeking to change individual behaviour, as propounded by the liquor industry. This approach would ideally involve implementing a full ban on alcohol advertising, supplemented with other policy interventions including increases in alcohol excise taxes; addressing alcohol availability through harmonisation of liquor outlet regulations across the provinces, and tighter controls on the hours of sale of alcohol; providing brief interventions for individual high-risk drinkers; and further reducing permissible blood alcohol concentration levels for drivers. ${ }^{6}$ Implementing a ban on alcohol advertising will not be easy, and many have warned of enormous job losses in the communications sector. ${ }^{5}$ The same argument was made in the lead-up to the ban on tobacco advertising, yet job losses did not materialise, and the advertising space vacated by the tobacco industry was largely taken up by cell phone companies. Other products are therefore likely to take up some of the advertising space if alcohol advertising is banned; for example, Sasol took over the sponsorship of the Springbok Rugby Team a few years ago when South African Breweries ended its sponsorship. The proposed regulations will still permit advertising of alcohol products at points of sale. Furthermore, efforts are under way to establish a Health Promotion Foundation in South Africa, funded possibly through a levy on alcohol and tobacco excise taxes. Thailand and Victoria State in Australia have used funds from health promotion foundations to buy advertising space to promote pro-health messages. Should this occur in South Africa, it is likely to provide an opportunity for revenue for advertising companies. We must also consider balancing losses in advertising jobs with the enormous financial and other savings that will result from a reduction in consumption and related harm. Banning alcohol advertising will also necessitate greater scrutiny of the digital media (FaceBook, Twitter and websites), satellite television and merchandising, to reduce the likelihood of the ban being subverted. ${ }^{11}$ Trade-offs are made all the time about what we can and cannot advertise, based on balancing harm and benefit. Surely the time has come to treat alcohol in the same way as tobacco products? 


\section{References}

1. Yach D, Strebel P, McIntyre D, Taylor S. Time to ban tobacco advertising. S Afr Med J 1989;75:410-411 2. World Health Organization. Global status report on alcohol and health 2011. Geneva: WHO, 2011. 3. Rehm J, Kehoe T, Rehm M, Patra J. Alcohol consumption and related harm in WHO Africa region in 2004. Toronto, Canada: Centre for Addiction and Mental Health, 2009.

4. Budlender D. National and provincial government spending and revenue related to alcohol abuse. Johannesburg: Soul City, 2009.

5. Paton C. Battle looms over shock move to ban liquor ad. Johannesburg: Business Day, 16 April 2012. 6. Anderson P, Chisholm D, Fuhr DC. Effectiveness and cost effectiveness of policies and programmes to reduce the harm caused by alcohol. Lancet 2009;373:2234-2246. [http://dx.doi.org/10.1016/S01406736(09)60744-3]

7. World Health Organization. Global Strategy to Reduce the Harmful Use of Alcohol. Geneva: WHO, 2010 8. World Health Organization. Global Status Report on Noncommunicable Diseases 2010. Geneva: WHO, 2010.

9. Institute of Alcohol Studies. Alcohol \& Advertising (IAS Factsheet). London: Institute of Alcohol Studies. http://www.ias.org.uk/resources/factsheets/advertising.pdf, 2007 (accessed 21 April 2012).

10. Casswell S. Alcohol harm - the urgent need for a global response. Addiction 2011;106:1205-1207. [http://dx.doi.org/10.1111/j.1360-0443.2011.03404.x]

11. De Bruijn, van den Wildenberg, van den Broek. Commercial promotion of Drinking in Europe: Key Findings of Independent Monitoring of Alcohol Marketing in five European Countries. Utrecht: The Dutch Institute for Alcohol Policy, 2012.

12. Advertising Standards Authority of South Africa. Code of Practice. http://www.asasa.org.za (accessed 21 April 2012).

13. Chen MJ, Grube JW, Bersamin M, Waiters E, Keefe DB. Alcohol advertising: what makes it so attractive to youth? J Health Commun 2005;10:553-565.

14. Anderson P, de Bruijn A, Angus K, Gordon R, Hastings G. Impact of alcohol advertising and media exposure on adolescent alcohol use: a systematic review of longitudinal studies.Alcohol Alcoholism 2009;44:229-43. [http://dx.doi.org/10.1093/alcalc/agn115]
15. Smith LA, Foxcroft DR. The effect of alcohol advertising, marketing and portrayal on drinking behaviour in young people: systematic review of prospective cohort studies. BMC Public Health 2009;9:51. [http://dx.doi.org/10.1186/1471-2458-9-51]

16. Snyder L, Milici F, Slater M, Sun H, Strazhakova Y. Effects of advertising exposure on drinking among youth. Arch Pediatr Adolesc Med 2006;160:18-24.

17. Hastings G, Brooks O, Stead M, Angus K, Anker T, Farrell T. Failure of self regulation of UK alcohol advertising. BMJ 2010;340. [http://dx.doi.org/10.1136/bmj.b5650]

18. Casswell S, Thamarangsi T. Reducing harm from alcohol: call to action. Lancet 2009;373:2247-2257. [http://dx.doi.org/10.1016/S0140-6736(09)60745-5]

. WHO Regional Committee for Africa. Reduction in the harmful use of alcohol: A strategy for the WHO African Region. Brazzaville: WHO Afro, 2010.

20. Saloojee Y. Tobacco Control. The South African Health Report: Chapter 22. http://www.hst.org.za/ sites/default/files/chapter22_00.pdf, 2000. (accessed 20 April 2012).

21. Department of Social Development. Ethekwini Resolution on Second Biennial Substance Abuse Summit, 25 March 2011. Pretoria: Department of Social Development, 2011.

22. Peer N, Bradshaw D, Laubscher R, Steyn K. Trends in adult tobacco use from two South African demographic and health surveys conducted in 1998 and 2003. S Afr Med J 2009;99:744-749.

23. Saffer D, Dave D. Alcohol consumption and alcohol advertising bans. Applied Economics 2002;34:1325-1334. [http://dx.doi.org/10.1080/00036840110102743]

24. Gallet CA. The demand for alcohol: A meta-analysis of elasticities. Aust J Agric Resour Econ 2007;51:121-135. [http://dx.doi.org/10.1111/j.1467-8489.2007.00365.x]

25. Babor T, Caetano R, Casswell S, et al. Alcohol: No Ordinary Commodity. Research and Public Policy, 2nd ed. New York: Oxford University Press, 2009.

26. Hollingworth W, Ebel BE, McCarty CA, Garrison MM. Prevention of deaths from harmful drinking in the United States: The potential effects of tax increases and advertising bans on young drinkers. J Stud Alcohol 2006;67:300-308.

Accepted 2 May 2012 